\title{
Occupational Hazards and Health Status of Trash Picker Children in Faisalabad City, Punjab, Pakistan
}

\author{
Zahira Batool ${ }^{1}$ \\ Madieha Akram² \\ Faiza Anjum ${ }^{3}$, \\ Sadaf Faiz ${ }^{4}$ \\ Muhammad lbrahim 5 \\ ${ }^{1}$ Associate Professor, Department of Sociology, GC University, Faisalabad, Pakistan \\ ${ }^{283}$ Ph.D Scholar of Sociology, GC University, Faisalabad, Pakistan \\ ${ }^{485}$ M.Phil Scholar of Sociology, GC University, Faisalabad, Pakistan \\ Corresponding author's email: faizaanjum723@gmail.com
}

Doi:10.5901/mjss.2015.v6n5s2p590

\section{Abstract}

Trash picking is an inferior, exploitative and inhumane economic activity; considered as the most vulnerable and neglected class in the urban informal labor market. The present study has been designed to examine the occupational environment and the hazards; and its effects on the health status of trash picker children. The snowball sampling technique was used to select the final sample unit; about 250 respondents (i.e. Trash picker children) in the age group of 7 to 18 years were selected. A welldesigned interviewed schedule (structured questionnaire) was used to collect the responses from the respondents. The study found that trash picker children faced various physical problems encircled by mosquitoes, flies, sharp metal, broken glass, broach, stray animals and feces lying around the garbage heaps. Most of them never worn gloves (97.2\%) and never use any instrument (87.2\%) for the self-protection. The working environment is hot and hazardous with a high risk of injuries; as the most (62.8\%) of children got injuries/cuts inflicted by sharp glass or mucronate metal. Also, the different type of diseases found among half percent of the children; in which most of them suffered from digestion problems (15.6\%), skin problems (13.6\%) and respiratory problems (9.2\%). These children are marginalized, cannot afford health services; received no treatment for injuries or many illnesses and preferred self-medication; sometimes visited to the local doctors or hospitals depending upon the diseases. Hence, there is a need to take an immediate step to provide safety equipment from the hazardous environment and intensive focus for the betterment of their health.

Keywords: Trash Picker Children; Working Environment; Occupational Risks; Health Status and Treatment Pattern.

\section{Introduction}

Trash picker or the paper picker is defined as one 'who eke out his/her livelihood by picking up waste materials from garbage heaps, road side dustbins, streets and houses for selling to the local junkyards, middleman, or nearby shops (Samson, 2009). They are required to collect waste paper, plastic, iron, scraps, bottles, tablet papers, syringes, rags, metal pieces, broken mirrors, wood, shoes, clothes, cardboards, cutlery and also collect food-waste for their consumption. Trash picking is an inferior and exploitative economic activity in the urban informal sector; it is considered as the most vulnerable, disadvantaged and neglected class in the urban informal labor market. Trash picking is one of the most dangerous and inhumane activity where they are exposed to unpleasant weather conditions, encircled by stray animals, infectious solid waste and spoil wastage of food items that may provoke them with many diseases (Niloufer, 2013). Due to the warm conditions of the city (Faisalabad), the wastage spoils quickly in the bins and spreading many infectious diseases. Also, the flies and mosquitoes buzz around them and sit on their faces caused a greater infectious risk for trash pickers. 


\subsection{Trash Picker Children}

The work of trash picking is easy to start, as they need no qualification, skill and investment in this profession; children by age 5 to 16 years also engaged in this activity. Children were forced to commence trash picking activity and they are required to collect recyclable items. These children earn their livelihood from the collection, separation and sale for recycling; most of them are the main source of income in their families. They live in unauthorized slums, in low-income residential areas; mostly in shanty towns, bridges, pavements and railway platforms without the facility of pure drinking water and electricity.

Trash picker children worked throughout the year except during extreme winters and rainy season (Barki \& Manhas, 2013). During the rainy season trash pickers are more likely to go hungry when materials are dirty and wet because it's difficult for them to collect due to the rain and mud. The basic rights of the children of taking healthy and nourished food, pure drinking water and having shelter are denied at the garbage heaps. There is also no place where they can sit and eat or keep their food safely. If they take food, it is unhealthy for them by the flies and mosquitoes at the dump sites. When these children are hungry; even have to eat shitty fruit from the garbage dumps, which shows a miserable picture of these scavengers and a remarkable question for society. In some conditions, they have to beg for food; it reflects the picture of weeklong starvation of child trash pickers. The risk of ill is very high because they consume unhealthy food and water and work in unhygienic conditions. They suffered from malnutrition, weakness, stunted growth and ill health in such impatient /pathetic situation. Trash picking activity not only exposed to the hazards and strains of their labor, but also deprived from education and training that could enable them to escape the poverty (Oza, 2013).

These children faced various physical problems such as bruises or cuts on their body and susceptible to infections and diseases because the most of the children never use any instrument for the protection of their hands and feet (Salam, 2013). The environments in which they work are hot and hazardous with a high risk of injuries and diseases; as the injuries and wounds inflicted by sharp glass or metal are common for trash picker's children. Some studies indicate that they got cuts, bruise, burns, dog-bites and allergies on their hands and feet, as they walk barefoot in garbage dumps collecting iron and glass pieces without worn gloves, and unattended infectious wounds causes septicemia and tetanus (Mari et al. 2007; Saxena, 2012). Several studies have been able to demonstrate that the health conditions of these children are very poor due to the work in hazardous environments; they are susceptible to diarrhea, malaria, frequently fever, stomach ache, respiratory problems, back and joint pain, skin diseases and tuberculosis (Andalib et al., 2011; Pathon, 2013; Oza, 2013). These children are marginalized socially and economically cannot afford health services, received no treatment for many illnesses and preferred self-medication (Thapa et al., 2009).

\subsection{Objectives of the Study}

- To identify the occupational risks faced by trash picker children.

- To examine the safety measurements during trash picking.

- To study the health problems and treatment patterns of trash picker children.

\section{Research Methods}

The prevalence of research phenomenon "trash picker children" is related to urban areas, especially in informal settlements. Faisalabad is a highly populous city of Pakistan; has become an extensive, very rapidly expanding city. It is characterized by large un-serviced and under-serviced areas (slums and katchi abadis) where the majority of the population lives in very poor and miserable conditions. The universe of the study was the urban informal settlements of Faisalabad city; the total number of informal settlements (katchi ababis/slums) in the city is 170 . The sample of trash picker children was gathered from 14 informal settlements (katchi ababis/slums) of Faisalabad city. The population of the study comprised of those children who were involved in trash picking activity in the age group of 7-18 years in these settlements. About eight informal settlements (katchi ababis/slums) were taken out of 14 through simple random technique; and about 250 respondents (i.e., Trash picker children) were selected through snowball sampling technique from the each selected informal settlement (katchi ababis/slums).

For the purpose of data collection; a well-designed interviewed schedule (structured questionnaire) was used to collect the responses from the respondents. It was most appropriate method because children were illiterate; not aware about the importance of such studies. Frequency distribution and percentages were used for the descriptive analysis to explain the data. The lowest and highest values of different variable are identified by frequency; the frequency distribution is counted each value that occurs in the set of data and then presented in the form of numbers and percentage 
distributions.

\section{Results and Discussion}

Table 1. Distribution of the Respondents Regarding Demographic data $(n=250)$

\begin{tabular}{|c|c|c|c|}
\hline Categories & $\mathbf{N}$ (Percentage) & Categories & $\mathbf{N}$ (Percentage) \\
\hline Sex & & \multicolumn{2}{|c|}{ Education } \\
\hline Boy & $197(78.8)$ & Illiterate & $168(67.2)$ \\
\hline Girl & $53(21.2)$ & Literate & $41(16.4)$ \\
\hline Age (years & & Primary & $22(8.8)$ \\
\hline $7-10$ & $65(26.0)$ & Middle + above & $19(7.6)$ \\
\hline $11-14$ & $127(50.8)$ & & \\
\hline $15-18$ & $58(23.2)$ & & \\
\hline
\end{tabular}

\subsection{Demographic Information}

The data of table 1 depict the personal information about the trash picker children. Almost two third percent of the children were boys that involved in trash picking. Boys are found to be dominated engaged in this activity because the work of trash picking is done on the roads, garbage heaps or collected the garbage from door to door; families did not allow their girls and preferred domestic work for them. Some girls also found to collect the items, but their age is less than 10 years old. All age groups of children do that work; about a half percent of them were between the age group of 11 to 14 years. Illiteracy is related to the poverty in developing countries, where the majority of its population is deprived of basic needs (food, pure water, health facilities); only make the effort to get meal twice a day don't think about the future of their children. The picture can be clearly seen in the results as majority 67.2 of the children were illiterate; never been inclined towards education.

Table 2. Distribution of the Respondent's Risks during Trash Picking $(n=250)$

\begin{tabular}{|l|c|c|c|}
\hline \multirow{2}{*}{ Statements } & Never & Sometimes & Always \\
\cline { 2 - 4 } & $\mathbf{N}$ (Percentage) & $\mathbf{N}$ (Percentage) & N (Percentage) \\
\hline Hurdles during trash picking & & & \\
\hline Flies/Mosquitoes & $0(0.0)$ & $32(12.8)$ & $218(87.2)$ \\
\hline Broken glasses/Sharp metals & $0(0.0)$ & $52(20.8)$ & $198(79.2)$ \\
\hline Feces \& Stray animals & $11(4.4)$ & $67(26.8)$ & $172(68.8)$ \\
\hline Chemical fumes & $181(72.4)$ & $41(16.4)$ & $28(11.2)$ \\
\hline Airborne dust & $53(21.2)$ & $127(50.8)$ & $70(28.0)$ \\
\hline Feel stress during trash picking & $138(55.2)$ & $79(31.6)$ & $33(13.2)$ \\
\hline Eating items from dump sites & $153(61.2)$ & $71(28.4)$ & $26(10.4)$ \\
\hline
\end{tabular}

\subsection{Hurdles during Trash Picking}

Table 2 presents the problems faced by children during trash picking; the majority $87.2 \%$ of respondents informed that flies and mosquitoes create disturbance always while they were trash picking because flies and mosquitos' bombinate around the garbage heaps. Most $79.2 \%$ and $68.8 \%$ of respondents said that broken glass/sharp metals and feces/stray animals come into contact always while they sought out the items respectively. Around $73.0 \%$ response was that they did not disturb by chemical fumes; and almost half percent were of the view that they faced problems sometimes by air born dust. Eerd (1996) concluded that they face various risks and hazards and expose to chemical risks due to toxic substances at dump sites.

\subsection{Feel Stress during Trash Picking}

Almost half percent of the children don't feel stress while trash picking; they said if they feel stressed to deal with and 
picking these items how they will collect a huge amount to earn just their basic needs. Despite, $31.6 \%$ and $13.2 \%$ feel stressed during trash picking sometimes and always respectively as shown in table 2. Children were on the view that, they are in problems when refreshable food, diapers and filthy clothes makes the atmosphere unpleasant; but they are compelled to work in this environment which almost all thought it's a dangerous and against the dignity of humans. In sorting process, a burden of good collection of items also puts the pressure on children leads to stress; because, if they unable to do that may too suffer with hunger.

\subsection{Eating Items from Dump Sites}

Children consumed polluted food items from the dumpsites when they feel hungry and not eatable things are available. A sizeable proportions of the data show the results that about one third percent of respondents eats food items (bread, fruit) from garbage heaps (see table 2 again). These things are unhealthy for them because exposure of dust and infectious particulate materials makes the food items pollutant and undernourishment that caused many diseases like stomachache, diarrhea, tetanus and asthma.

Table 3. Distribution of the Respondent's use of Safety Equipment's $(n=250)$

\begin{tabular}{|l|c|c|c|}
\hline \multirow{2}{*}{ Statements } & Never & Sometimes & Always \\
\cline { 2 - 4 } & $\mathbf{N}$ (Percentage) & $\mathbf{N}$ (Percentage) & $\mathbf{N}$ (Percentage) \\
\hline Seasonal clothes & $41(16.4)$ & $152(60.8)$ & $57(22.8)$ \\
\hline Worn shoes & $7(2.8)$ & $52(20.8)$ & $191(76.4)$ \\
\hline Worn mask & $247(98.8)$ & $3(1.2)$ & $0(0.0)$ \\
\hline Worn gloves & $250(100.0)$ & $0(0.0)$ & $0(0.0)$ \\
\hline Use of tools & $218(87.2)$ & $20(8.0)$ & $12(4.8)$ \\
\hline
\end{tabular}

\subsection{Safety Equipment's}

The results clearly indicate that these children are deprived from basic needs and instruments which are essential for their safety from infections and polluted environment. Trash pickers are vulnerable at high risks that caused injuries and communicable diseases. The majority $60.8 \%$ of the children were sometimes worn seasonal clothes in rainy or hot season; and mostly $76.4 \%$ were always worn shoes at work place (see table 3). This study contradicts with the results gave by Sekar (2004) as he concludes that only 41.84 percent of the total rag picker children worn foot wears. Majority $98.8 \%$ of children said they were never worn mask; even they did not know about the mask. It is also found that $100 \%$ of respondents were never worn gloves when they collected trash; they sought out the recyclable material with bare hands from the garbage heaps. Among all, the majority $87.2 \%$ of children were never used any tools while picking the trash; a small proportion of children used tools like wood and stick.

Table 4. Distribution of the Respondent's Health Status and Treatment Patterns $(n=250)$

\begin{tabular}{|c|c|c|c|}
\hline Categories & $\mathbf{N}$ (Percentage) & Categories & $\mathrm{N}$ (Percentage) \\
\hline Injuries & & Diseases & \\
\hline $\begin{array}{l}\text { Yes } \\
\end{array}$ & $157(62.8)$ & Tuberculosis & $2(0.8)$ \\
\hline No & $93(37.2)$ & Fever & $7(2.8)$ \\
\hline Types of injuries & & Headache & $9(3.6)$ \\
\hline Animal bite & $7(2.8)$ & Cough & $16(6.4)$ \\
\hline Bruise & $16(6.4)$ & Back \& joint pain & $17(6.8)$ \\
\hline Cuts & $134(53.6)$ & Respiratory problems & $23(9.2)$ \\
\hline Not applicable & $93(37.2)$ & Skin problem & $34(13.6)$ \\
\hline \multicolumn{2}{|l|}{ Treatment of injuries } & Digestion problem & $39(15.6)$ \\
\hline \multirow{2}{*}{ Ointment of betel leaves (pan ka pata) } & \multirow{2}{*}{$15(6.0)$} & Not ill & $103(41.2)$ \\
\hline & & \multicolumn{2}{|c|}{ Health status since the last one year } \\
\hline Salt & $17(6.8)$ & Good & $11(4.4)$ \\
\hline Medicine by doctor & $20(8.0)$ & Average & $71(28.4)$ \\
\hline Sand/dust & $34(13.6)$ & Suffering Diseases & $168(67.2)$ \\
\hline
\end{tabular}




\begin{tabular}{|l|l|l|c|}
\hline Ghee/desi ghee/oil & $71(28.4)$ & \multicolumn{2}{|l|}{ Consult for treatment } \\
\hline Not applicable & $93(37.2)$ & Hakeem & $11(4.4)$ \\
\hline & & Homeopathic & $13(5.2)$ \\
\hline & & Hospital & $20(8.0)$ \\
\hline & & Self-treatment & $57(22.8)$ \\
\hline & & Local doctor & $149(59.6)$ \\
\hline
\end{tabular}

\subsection{Injuries and types of Injuries}

Table 4 shows that a significant $62.8 \%$ of respondents were injured at work place. Their bare hands and feet may injure with sharp glass pieces lying hidden in the garbage heaps and develop into rankle wounds. The data about the different types of injuries reveals that among the all injured children, the majority $53.6 \%$ of them got cuts during the trash picking. A number of cuts are viewed on their hands, arms and foot during the study. They roam around the garbage heaps without shoes, gloves and tools (stick, wood); despite, many sharp metals caused the cuts. Tripathy (1997) indicated that mostly child rag (trash) pickers received cuts on their hands when collecting rusted iron pieces; others, Barki \& Manhas (2013) concluded that child trash pickers faced various physical hazards during the work such as cuts/bruises on their body.

\subsection{Treatment of Injuries}

In getting injuries/cuts, mostly $28.4 \%$ and $13.6 \%$ apply desi ghee/oil and sand/dust respectively; some $6.8 \%$ apply salt on the affected parts; only $8.0 \%$ goes to the local doctors as shown in table 4 . Children with the view that only go to the doctors for treatment when the wounds are not cured because they can't afford the expenditures for it. They apply sand dust on the wounds or tying with a piece of cloth available in the locality even if it is from the garbage dump (Sekar, 2004).

\subsection{Diseases}

The results state the diseases about trash picker children when the study was conducted. The study indicates that most of the trash picker children suffered from digestion problems (15.6\%), skin problems (13.6\%) and respiratory problems $(9.2 \%)$ due to the infectious atmosphere of dump sites and wastes. It is concluded that most having digestion problems because of unhygienic food, even sometimes eats items found in the garbage heaps. A study conducted in Vietnam by Nguyen et al. (2000), $17 \%$ were children amongst all, it is found that most of the children suffered from stomach ache, headache and cough. By another, Tidke (2014) almost $75 \%$ of rag picker children are facing different health problems; they suffered from infections, headache, skin diseases and allergic diseases.

\subsection{Health Status since the Last One Year}

Illness is a common phenomenon among the trash picker children. They suffer from several kinds of diseases due to their working and living conditions; the working sites and homes are infectious where the trash is collected and kept for separation. The findings also reveal the health status of trash picker children since the last one year; at most $67.2 \%$ of respondents informed that they were suffering from diseases (see table 4). Sekar (2004) studied that rash pickers are subject to illness due to cold, improper food and exposure to contamination and bacteria.

\subsection{Consult for Treatment}

Most, $59.6 \%$ of the children were consulted the local doctors when they ill; and a significant $22.8 \%$ of them were not consulted with anyone (see table 4 again); they do the treatment by self. They prefer self-treatment; takes medicines on their own and gone to the local doctors or hospitals depending upon the seriousness diseases. Most of the children were of the view that "it is difficult to afford basic needs (roti/chapati) in these expensive days you are asking about treatment of diseases". During the study, it was found that the local doctors in these informal settlements are quacks without formal medical education and having fake degrees. On falling illness, 47.14 percent of the trash picking children has consulted the local doctor and 29.95 percent had self-treatment (Sekar, 2004). Almost all waste pickers were suffering from some sorts of health problem; they don't care about their health and manage by themselves, especially in terms of injury 
(Andalib et al., 2011).

\section{Conclusion}

Trash picking is an inhuman economic activity that is harmful for their health because of work in an unhygienic and unpleasant environment; but there is no other opportunity for livelihoods. It is concluded that trash picker children roam around the garbage heaps with bare hands and feet; broken glasses, needles, sharp metals, discard pieces come into contact while they are working at dump sites. Injuries are found to be common among trash picker children; many cuts were observed on their bare hands and feet. The most common diseases amongst these children were respiratory problems, digestion problems and skin problems. Regarding their consultations for treatment, they cannot afford treatment by the doctors due to the reasons of lack of awareness and poverty; some of them preferred self-treatment or by local doctors even they know they are quacks and not real doctors. By an observation, it was observed that the doctors of these settlements are quacks or having fake certificates without any medical training. They visited for doctors in the serious conditions or when the injuries become extremely septic wounds. Hence, It is remarked that there should be open free of cost dispensary to provide them medical support. Children work for long hours in hazardous environment; immediate steps should be taken to provide safety equipment from the hazardous environment such as chappls, masks, gloves and clothes that save them from heat and winter season.

\section{References}

Andalib, N., Faruquee, M. H., Fairoz, S. W., Chaklader, M. A., Lahiry, S., \& Yasmin, N. (2011). Abstract: Health Problems Among the Adolescent Waste Pickers in Dhaka City. Sub Journal of Public Health, 3-4(2-1): 53-57.

Barki, M., \& Manhas, S. (2013). Working Conditions of Rag Picking Children in Jammu City, India. Zenith International Journal of Multidisciplinary Research, 3(2), ISSN 2231-5780.

Eerd, M. van. (1996). The Occupational Health Aspects of Waste Collection and Recycling: A Survey of the Literature. UWEP Working Document 4, Part I. WASTE, Gouda, The Netherlands.

Mari, S. et al. (2007). Ragpickers. [Online] available: www.npr.org.

Niloufer, S., Swamy, A. V. V. S., \& Devi, K. S. (2013). Waste Collection by Rag Pickers in the Cities-A Brief Report. PARIPEX - Indian Journal of Research, 2(4): 211-214.

Nguyen, H. T. L., Chalin, C. G., Lam, T. M. and Maclaren, V. W. (2000). Health \& Social Needs of Waste Pickers in Vietnam. [Online] available: dm.org.in/attachments/article/17 waste \% 20 Picker\% 20Study.pdf.

Oza, D. (2013). Adolescence Teachings to Street Children Through Life Skill Approach: An Experience. Indian e-Journal on Teacher Education (IEJTE), Bi-Monthly e-Journal, 1 (4): 1-6.

Pathon, A. (2013). Indonesia's Boom Eludes Trash Pickers. Copyright Deutsche Presse- Agentur. [Online] available: http://www. brecorder.com/articles-a-letters/=:/1181033: indonesias-boom-eludes-trash-pickers/?date=2013-05-01.

Salam, A. (2013). Living and Educational Conditions of Child Rag Pickers on Base of Solid Waste of Guwahati City in Assam. Research Journal of Humanities and Social Sciences, 4(2): 185-189.

Saxena, D. (2012). A Research Report on Rag Pickers of Jaipur, for Enhancing Quality of Life of Rag pickers. [Online] available: http://www.Kuhadtrust.org/pdf/ragpickers.pdf.

Samson, M. (2009). Refusing to be Cast Aside: Waste Pickers Organising Around the World. Published by Women in Informal Employment: Globalizing and Organizing (WIEGO) Cambridge, MA. Publisher: WIEGO. [Online] available: http://wiego.org/sites/ wiego.org/files/publications/files/Samson-Refusing-to-be-Cast-Aside-Wastepickers-Wiego-publication-English.pdf.

Sekar, H. R. (2004). Child Labor in Urban Informal Sector: A Study of Rag Pickers in Noida. V.V. Giri National Labor Institute (An Autonomous body of the Ministry of Labor and Employment). Sector-24, Noida.pdf.

Thapa, K., Ghatane, S., \& Riml, S. P. (2009). Health Problems Among the Street Children of Dharan Municipality, Nepal. Kathmandu University Medical Journal, 7(3): 272-279.

Tidke, S. J. (2014). A Study of Child Rag Pickers in Akola City of Maharashtra. Indian Streams Research Journal, IV(III): 1-6. doi: 10.9780/22307850.

Tripathy, S. N. (1997). Paperback: 194 pages Publisher: Mohit Publications Language: English. ISBN-10:8174450300. ISBN-13:9788 174450302. [Online] available: http:// www.amazon.com /Migrant-child-labour-India-Tripathy/dp/8174450300. 